\title{
Multimodal management of pediatric carotid body tumors: a systematic review and case illustrations
}

\author{
Manish Kuchakulla, BS, Ashish H. Shah, MD, Valerie Armstrong, BS, Sarah Jernigan, MD, MPH, \\ Sanjiv Bhatia, MD, and Toba N. Niazi, MD \\ Department of Neurosurgery, University of Miami, Florida
}

OBJECTIVE Carotid body tumors (CBTs), extraadrenal paragangliomas, are extremely rare neoplasms in children that often require multimodal surgical treatment, including preoperative anesthesia workup, embolization, and resection. With only a few cases reported in the pediatric literature, treatment paradigms and surgical morbidity are loosely defined, especially when carotid artery infiltration is noted. Here, the authors report two cases of pediatric CBT and provide the results of a systematic review of the literature.

METHODS The study was divided into two sections. First, the authors conducted a retrospective review of our series of pediatric CBT patients and screened for patients with evidence of a CBT over the last 10 years (2007-2017) at a single tertiary referral pediatric hospital. Second, they conducted a systematic review, according to Preferred Reporting Items for Systematic Reviews and Meta-Analyses (PRISMA) guidelines, of all reported cases of pediatric CBTs to determine the characteristics (tumor size, vascularity, symptomatology), treatment paradigms, and complications.

RESULTS In the systematic review ( $n=21$ patients [includes 19 cases found in the literature and 2 from the authors' series]), the mean age at diagnosis was 11.8 years. The most common presenting symptoms were palpable neck mass $(62 \%)$, cranial nerve palsies (33\%), cough or dysphagia (14\%), and neck pain (19\%). Metastasis occurred only in $5 \%$ of patients, and $19 \%$ of cases were recurrent lesions. Only $10 \%$ of patients presented with elevated catecholamines and associated sympathetic involvement. Preoperative embolization was utilized in $24 \%$ of patients (external carotid artery in 4 and external carotid artery and vertebral artery in 1). Cranial nerve palsies (cranial nerve VII [n=1], IX [ $n=1], X[n=$ 4], XI [n=1], and XII [n=3]) were the most common cause of surgical morbidity ( $33 \%$ of cases). The patients in the authors' illustrative cases underwent preoperative embolization and balloon test occlusion followed by resection, and both patients suffered from transient Horner's syndrome after embolization.

CONCLUSIONS Surgical management of CBTs requires an extensive preoperative workup, anesthesia, and multimodal surgical management. Due to a potentially high rate of surgical morbidity and vascularity, balloon test occlusion with embolization may be necessary in select patients prior to resection. Careful thorough preoperative counseling is vital to preparing families for the intensive management of these children.

https://thejns.org/doi/abs/10.3171/2018.8.PEDS18393

KEYWORDS carotid body tumor; paraganglioma; embolization; oncology

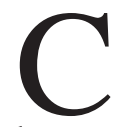
AROTID body tumors (CBTs), also known as paragangliomas, are rare vascular tumors arising from neuroendocrine cells within the carotid body. CBTs have a prevalence of 1:30,000 and represent more than $50 \%$ of head and neck paragangliomas. ${ }^{31}$ These tumors may produce significant symptomatology, including sympathetic surges from catecholamine release, palpable neck mass, hoarseness, dysphagia, and Horner's syndrome. ${ }^{19,39}$ In the adult population, there is significant morbidity and mortality associated with the treatment of these lesions. While resection is the primary method of treatment for these tumors, this modality is technically challenging due to intimate associations with cranial nerves and the arterial system. ${ }^{9}$ Due to these surgical challenges, preopera-

ABBREVIATIONS BTO = balloon test occlusion; $C B T=$ carotid body tumor; $C N=$ cranial nerve; $E C A=$ external carotid artery; $I C A=$ internal carotid artery; MIBG = iodine123-meta-iodobenzylguanidine; PRISMA = Preferred Reporting Items for Systematic Reviews and Meta-Analyses.

SUBMITTED June 27, 2018. ACCEPTED August 27, 2018.

INCLUDE WHEN CITING Published online December 7, 2018; DOI: 10.3171/2018.8.PEDS18393. 
tive embolization is widely utilized to provide surgeons with greater ease while reducing complications. ${ }^{35}$ While CBTs most commonly affect adults in their 3rd to 5th decade of life, they are exceedingly rare in the pediatric population..$^{39}$ With relatively few pediatric cases reported in the literature ( $<20$ cases), surgical morbidity and optimal treatment paradigms for pediatric patients have yet to be established. Children may be especially vulnerable to these neoplasms due to their low intravascular volume, autonomic dysregulation, proximity to/infiltration of critical neurovascular structures, and potential associations with genetic syndromes.

Here, we present two new cases of pediatric CBT and present a systematic review of the literature to further understand the multimodal treatment of these lesions.

\section{Methods}

\section{Systematic Review}

Based on the Preferred Reporting Items for Systematic Reviews and Meta-Analyses (PRISMA) guidelines, the authors performed a database search of PubMed to identify English-language literature published between 1968 and 2018, searching MeSH terms from PubMed, with combinations of keywords that describe pediatric paragangliomas, CBTs, and glomus tumor. Articles were limited to those written in English, those that included pediatric patients (under the age of 18 years), and those in which surgery was performed. Tumors were confirmed to be paragangliomas by histological classification based on features common to CBTs and adrenal paragangliomas. Articles were limited to those discussing tumors in the neck. Eighteen full-length articles were assessed; from these 4 were excluded and 14 were included in this analysis. Cross-referencing articles found by the initial search yielded no additional relevant articles (Fig. 1).

\section{Results}

Through our literature review, we identified 19 cases over the last 50 years, plus an additional 2 new cases from our institution, for a total of 21 . The mean age at diagnosis was 11.8 years and there were a greater number of females. All patient demographics are listed in Table 1. A palpable neck mass was seen in $62 \%(n=13)$ of patients, with tumors most commonly located in the right carotid body (62\%). Of the 16 patients with tumor size reported, $44 \%$ presented with large tumors ( $>5 \mathrm{~cm}$ in diameter); see Table 2. Most patients in our series had a successful grosstotal resection $(n=18)$, one had subtotal resection, one received chemotherapy, and one underwent radiotherapy. Preoperative embolization was used in $24 \%$ of the cases; no cases of preoperative embolization resulted in any complications. The surgical morbidity rate was $33 \%$ (cranial nerve $[\mathrm{CN}]$ palsy, $\mathrm{n}=7$ ). Recurrence was noted in $19 \%(\mathrm{n}$ $=4$ ) of patients. Metastasis was evident only in one case $(5 \%)$ and two patients displayed elevated catecholamine levels $(10 \%)$. Overall, $66 \%$ of patients were documented to have follow-up with no evidence of disease or complications after the first treatment. Overall survival was $95.2 \%$, with a mean follow-up duration of 39.5 months.

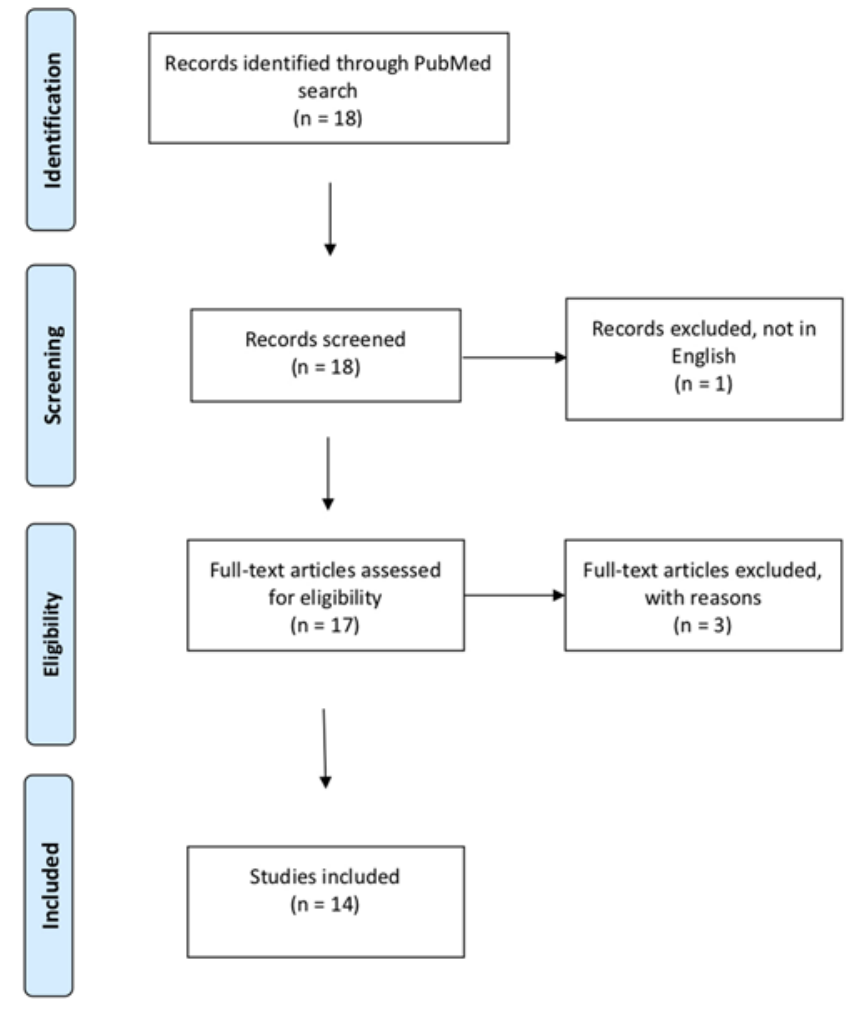

FIG. 1. PRISMA flow diagram. Figure is available in color online only.

\section{Illustrative Cases From Our Institution Case 1}

This 8-year-old girl presented with a nontender palpable neck mass. She first noticed the mass after suffering recurrent streptococcal pharyngeal infections. The child reported no associated weight loss, dysphagia, hoarseness, fever, or signs of sympathetic surges. CT and MRI revealed a right cervical neck mass at carotid bifurcation without visualization of the right internal jugular on CT angiography. An MIBG scan (iodine-123-meta-iodobenzylguanidine nuclear scan) was negative for neuroendocrine tumor, and therefore the patient underwent a needle biopsy that yielded results consistent with paraganglioma. Prior to resection, she underwent diagnostic angiography with a balloon test occlusion (BTO) of the right internal carotid artery (ICA). The patient passed the BTO and had an uneventful embolization of her external carotid artery (ECA) feeders (Fig. 2). The patient was placed under general endotracheal anesthesia and the tumor was resected. Intraoperatively, we noted bleeding, and also noted was gross infiltration of the ICA lumen, which required parent vessel sacrifice. Collateral feeders from the ECA and vertebral artery were also ligated to facilitate resection. Intraoperatively, mild electroencephalogram slowing was noted, and somatosensory evoked potentials remained stable (estimated blood loss $<50 \mathrm{ml}$ ). Postoperatively, the patient developed mild hoarseness (CN X) and right-sided Horner's syndrome. Over the ensuing weeks, the transient vagal neuropathy and Horner's syndrome improved. Follow-up after 2 years showed resolution of the Horner's syndrome and vagal neuropathy and no further complications. 


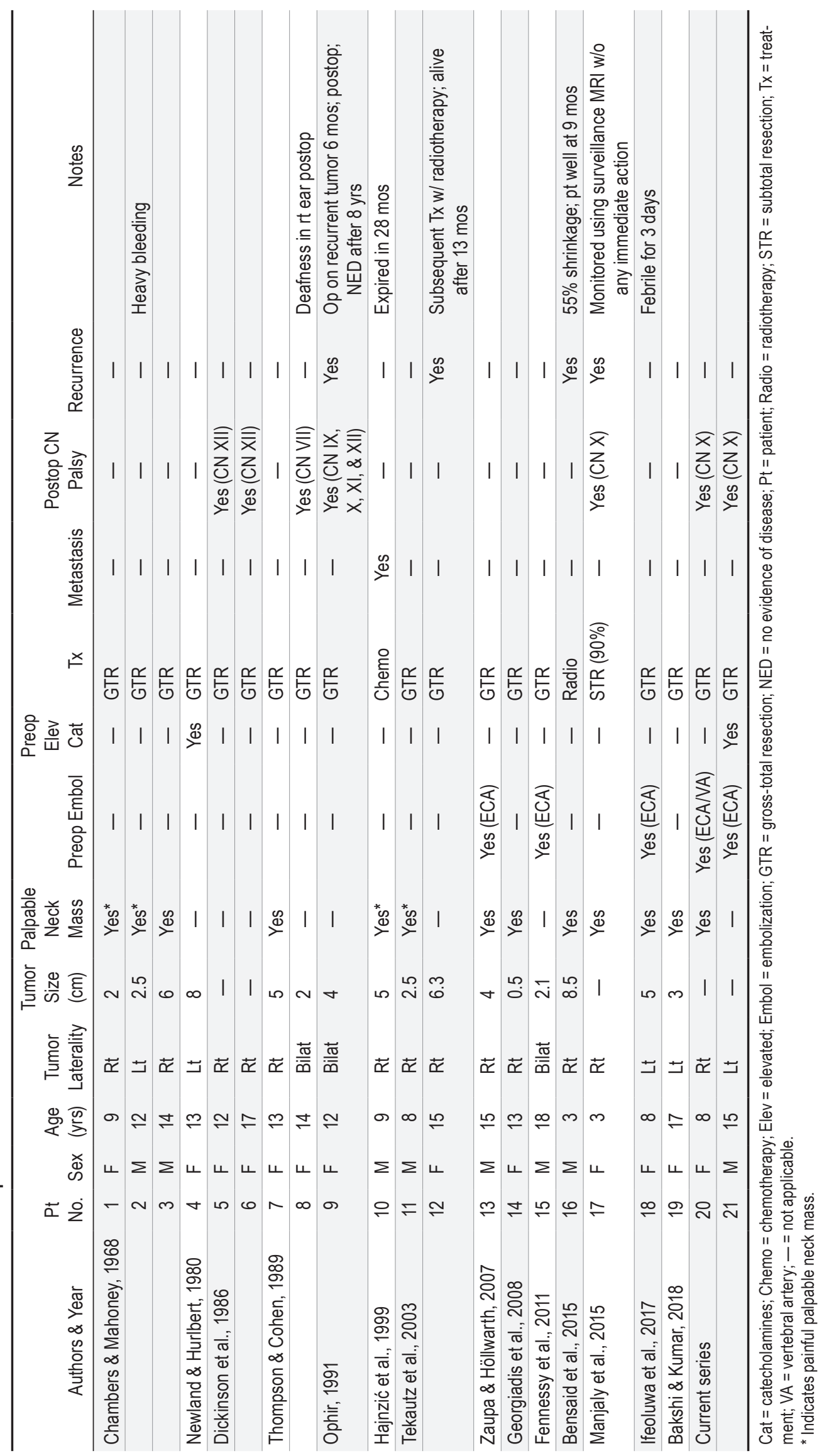


TABLE 2. Baseline characteristics of 21 subjects

\begin{tabular}{|c|c|}
\hline Pt Characteristics & Value \\
\hline Age (IQR), yrs & $11.8(3-18)$ \\
\hline \multicolumn{2}{|l|}{ Sex, no. (\%) } \\
\hline Male & $13(62 \%)$ \\
\hline Female & $8(38 \%)$ \\
\hline \multicolumn{2}{|l|}{ Presenting symptoms, no. (\%) } \\
\hline Painless neck mass & $9(43 \%)$ \\
\hline Painful neck mass & $4(19 \%)$ \\
\hline Cough/dysphagia & $3(15 \%)$ \\
\hline Elevated catecholamines & $1(5 \%)$ \\
\hline \multicolumn{2}{|l|}{ Tumor size, no. } \\
\hline$<5 \mathrm{~cm}$ in diameter & 9 \\
\hline$\geq 5 \mathrm{~cm}$ in diameter & 7 \\
\hline \multicolumn{2}{|l|}{ Laterality of tumor, no. (\%) } \\
\hline Rt carotid body & $13(62 \%)$ \\
\hline Lt carotid body & $5(24 \%)$ \\
\hline Bilat & $3(15 \%)$ \\
\hline \multicolumn{2}{|l|}{ CN palsy postop, no. } \\
\hline VII & 1 \\
\hline IX & 1 \\
\hline$x$ & 4 \\
\hline$X I$ & 1 \\
\hline XII & 3 \\
\hline \multicolumn{2}{|l|}{ Preop embol, no. } \\
\hline ECA & 4 \\
\hline ECA \& VA & 1 \\
\hline
\end{tabular}

$I Q R=$ interquartile range.

\section{Case 2}

This 15-year-old boy presented for consultation for right-sided facial flushing with hyperhidrosis. He was noted to have left-sided Horner's syndrome as well as elevated urine metanephrines. An MIBG scan was negative for neuroendocrine tumor. After further evaluation, MRI/MR angiography revealed a left-sided neck mass along the left carotid artery displacing the carotid artery and the ECA and ICA anterolaterally. When the patient's Horner's syndrome and CN X neuropathy worsened, it was determined that the patient would benefit from preoperative embolization followed by resection of the mass. Preoperatively, the patient underwent embolization and BTO through the superior ECA feeders. The following day, he was taken to surgery, placed under general endotracheal anesthesia, and the operation proceeded with no complications (estimated blood loss $<50 \mathrm{ml}$ ). Tight blood pressure control was advised during this procedure. The common facial vein, large feeders coming from the inferior pole of the tumor, and one superior feeding vessel were divided during the operation with use of a microscope for visualization. The entire tumor was removed, and histopathology confirmed the diagnosis of paraganglioma (Fig. 3). The patient is doing well at 2 years following treatment with an improving left-sided Horner's syndrome.

\section{Discussion}

CBTs are rare tumors that account for a very small portion of all neoplasms in the head and neck region. The tumor was first described by Albrecht von Haller in $1743 .{ }^{24} \mathrm{CBTs}$ are normally slow-growing and are generally asymptomatic for long periods of time. The majority of patients present with unilateral tumors, but $3 \%-4 \%$ can be bilateral. ${ }^{22}$ Due to their slow growth, CBTs may go unnoticed for long periods of time. Symptoms are eventually caused by the mass of the lesion or by the lesion's involvement of cranial nerves. Common symptoms include neck pain, hoarseness, dysphagia, Horner's syndrome, cough, and tongue weakness. ${ }^{1,3}$ The tumor mass exhibits only medial-to-lateral mobility and unique pulsations can be felt immediately anterior to the lesion. ${ }^{3,25}$ Cranial nerve involvement is quite rare, only occurring up to $20 \%$ of the time, often involving the glossopharyngeal, hypoglossal, and vagal nerves..$^{16,41}$

\section{Etiology}

The specific cause of these tumors is unknown. However, a higher prevalence of CBTs has been identified in people residing at higher altitudes in hypoxic conditions. Saldana et al. reported that Peruvian patients residing at high altitude presented with carotid body hyperplasia 10 times more frequently than individuals at sea level. ${ }^{36}$ Low $\mathrm{pO}_{2}$ is a major determinant of chemoreceptor cell activity, and thus it has been postulated that hypoxic conditions may be a stimulus for carotid body hyperplasia. In addition, several genes have been suspected in the development of these tumors, such as NF1, RET, SDHB, and TMEM127. ${ }^{28}$ It has been suggested that individuals who carry CBT susceptibility mutations and are subjected to chronic hypoxia often develop tumors at an earlier age. ${ }^{20}$

\section{Diagnosis}

The differential diagnosis for these lesions commonly includes enlarged lymph nodes, branchial cleft cysts, parotid gland tumors, thyroid tumors, neurogenic tumors, and carotid artery aneurysms. ${ }^{3}$ The combination of classic clinical symptomatology (hoarseness with sympathetic dysregulation) and radiological findings (tumor in the carotid bifurcation) can help seal the preoperative diagnosis. ${ }^{7}$ Newer techniques, such as MR angiography, have also been utilized for accurate diagnosis and preoperative planning..$^{14}$ Ancillary radiological studies, such as positron emission tomography (PET) scanning or nuclear medicine MIBG, may also be helpful in identifying foci of increased metabolism or neuroendocrine production, respectively. ${ }^{14}$ Additional tests such as urine metanephrine testing should also be performed if a diagnosis of CBT is suspected, although these tests can show normal findings, as indicated in our case illustrations. Given their high vascularity and proximity to large neurovascular structures, incisional biopsies are usually not recommended. ${ }^{13}$ In case 1 , a needle biopsy was performed due to the uncertainty of diagnosis in the setting of negative adjuvant tests (negative MIBG and urine metanephrines).

\section{Anesthesia}

Preoperative management of blood pressure is impor- 
Kuchakulla et al.
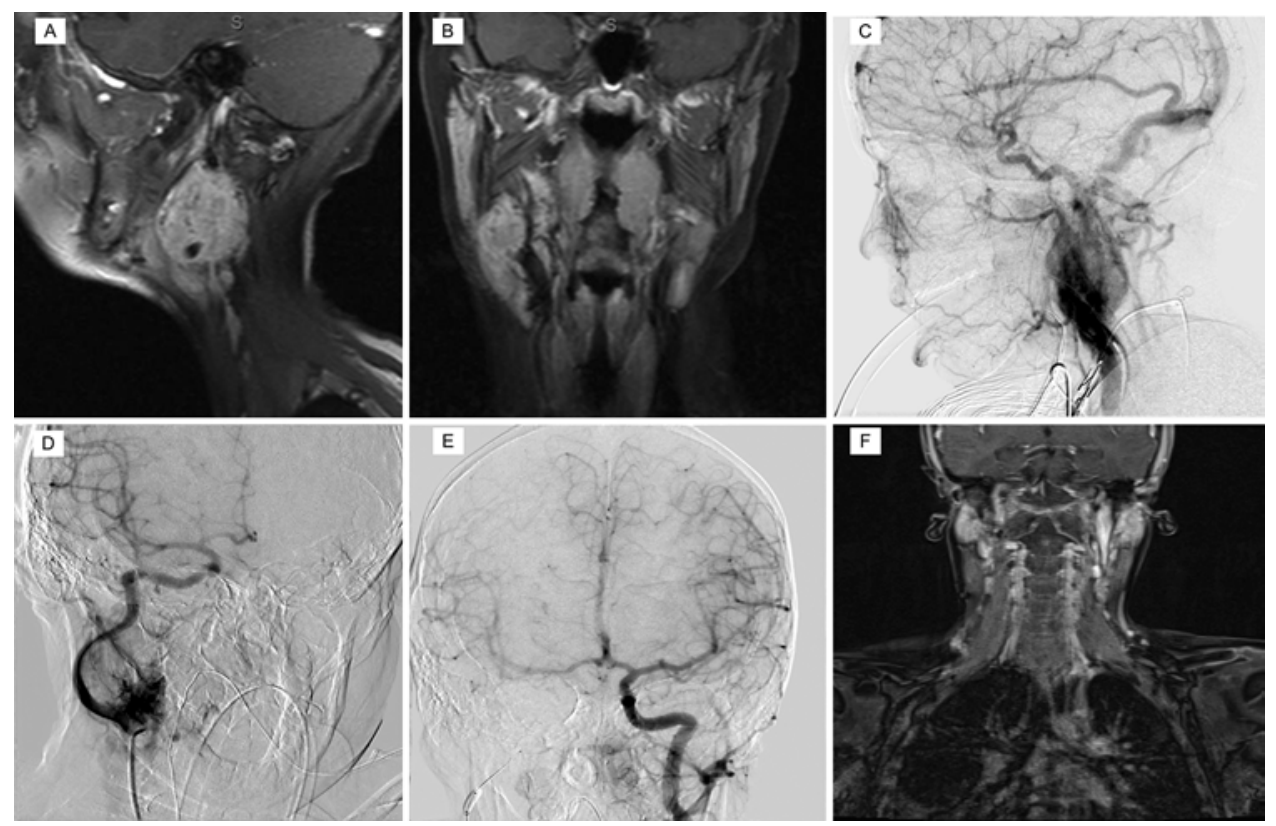

FIG. 2. An 8-year-old girl with a neck mass. Sagittal (A) and coronal (B) MR images demonstrating a 3.4-cm contrast-enhancing lesion at the carotid bifurcation. Lateral (C) and anterior (D) views of right common carotid artery cerebral angiograms demonstrating arterial blush within lesion with ECA and ICA feeders. BTO of the right ICA (E) demonstrating adequate filling of right ICA.

Postoperative coronal MR image (F) demonstrating gross-total resection of cervical lesion.

tant for limiting surgical complications and should be considered in all operative cases. Although in most cases the tumors are not actively secreting, some paragangliomas secrete catecholamines, making the risk of surgery greater. Whether or not the tumor is actively secreting catecholamines, there is a risk that catecholamine surge can occur during resection and lead to severe vasoconstriction through alpha receptors and cause a hypertensive crisis. Thus, in order to prevent this from occurring, it is important to utilize alpha blockers preoperatively, such as phenoxybenzamine. Phenoxybenzamine is a robust blocker that is able to inhibit alpha activation and is not easily overcome by any catecholamine surge. ${ }^{11}$ Following adequate alpha blockade, beta blockers may also be utilized to control heart rate..$^{12}$ Adequate blood pressure control is important to avoid hypertensive crises during surgery.

\section{Treatment}

Typical treatment of these lesions requires surgical resection coupled with preoperative angiography and potential embolization. For children, dedicated angiography may help delineate important vascular feeders, and embolization may prevent excessive blood loss during surgery. ${ }^{32,42}$ After embolization of vascular feeders, reduced intraoperative blood loss may improve the surgeon's visibility and reduce the risk of inadvertent nerve injury. ${ }^{21,34,43}$ During angiography, a BTO can be performed, which can determine whether the patient can tolerate a carotid artery sacrifice during surgery or preoperatively. It is critically important to evaluate ischemic tolerance using BTO to prevent stroke. BTO results are most commonly evaluated during either clinical or radiological examination. In the clinical evaluation method, hand grip, muscle strength, language, memory, and facial strength are assessed several times over a 30-minute period. On the other hand, adjuvant imaging can be used to measure the symmetry of arterial/ venous filling and determine whether there is sufficient collateral blood flow. ${ }^{38}$ These evaluations are important when designing the patient's treatment plan to include embolization. Although not always necessary, embolization may provide an additional safeguard for resection of these difficult tumors in children. However, the added benefit of preoperative embolization must be weighed against its po-

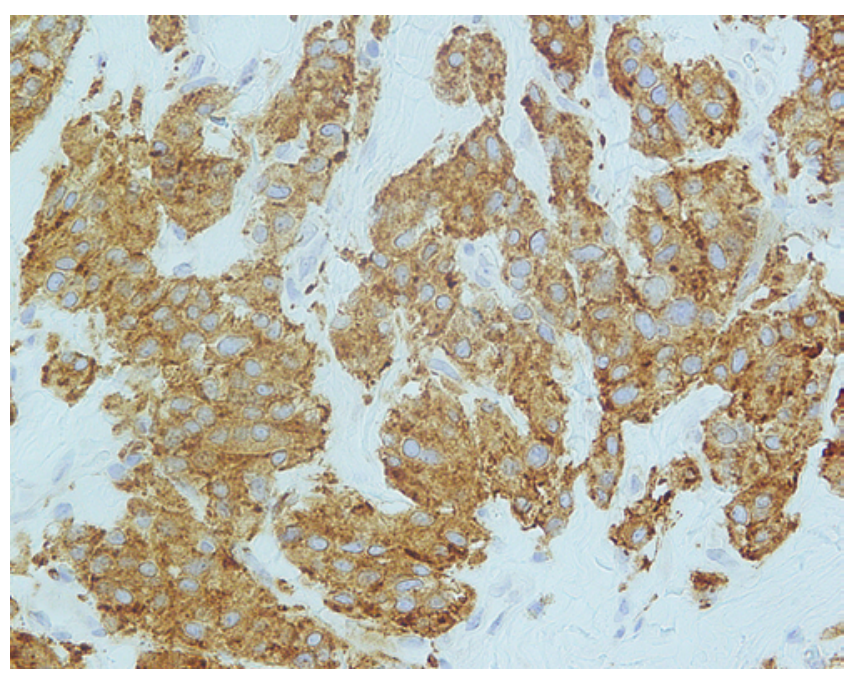

FIG. 3. Immunohistochemistry on formalin-fixed, paraffin-embedded tissue was used for diagnosis. Type 1 chief cells stain positively for synaptophysin, which confirms the neuroendocrine origin and supports the diagnosis of paraganglioma. Figure is available in color online only. 


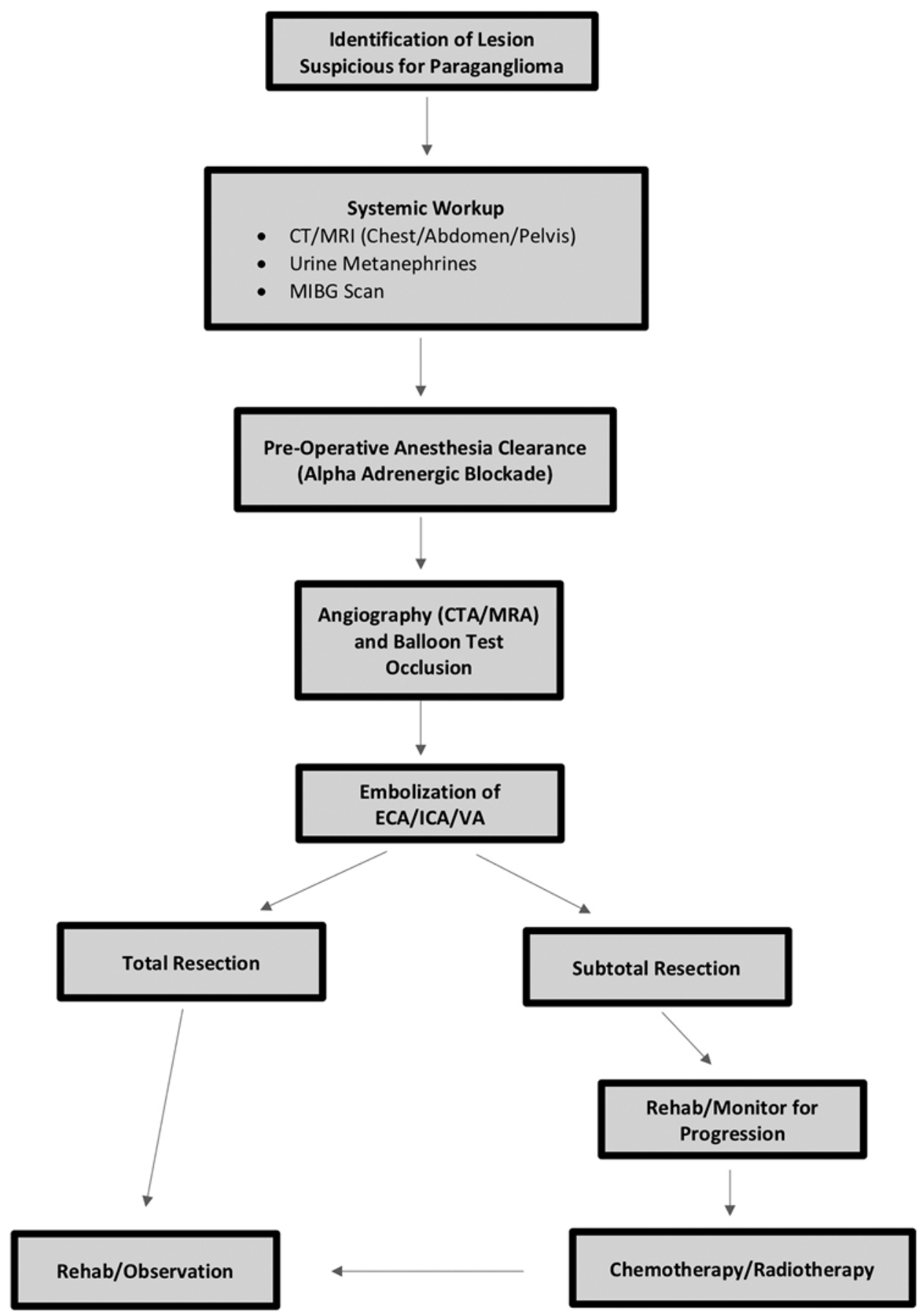

FIG. 4. Treatment paradigm for $C B T$ management. $C T A=C T$ angiography; $M R A=M R$ angiography; $V A=$ vertebral artery.

tential risks. In the setting of a failed BTO, the aggressiveness of embolization and the subsequent resection should be tailored accordingly. As in case 1, Horner's syndrome may develop after embolization; however, more serious complications have been reported with particles, including embolic stroke and postembolization inflammatory swelling. ${ }^{29,45}$ In children, clinicians should be wary of these risks as they counsel patients prior to surgery.

Gross-total resection is often considered the mainstay optimal treatment choice for CBTs. It has been reported that recurrence is highly unlikely when gross-total resection is achieved. ${ }^{27}$ In our series, recurrence was only identified in $5 \%$ of pediatric cases who underwent gross-total resection with 6 weeks of follow-up. During surgery, early identification of critical neurovascular structures (ECA, ICA, jugular vein, and vagus nerve) is essential prior to debulking. Since these tumors may be intimately involved in the adventitial layers of the carotid artery, caution must be given to defining a plane or "white line" between the tumor and the artery. ${ }^{5,18}$ Once a diagnosis is suspected, early 
and aggressive resection is recommended to prevent tumor growth, malignant degeneration, and avoid morbidity. ${ }^{33}$

The ability for total resection is dependent on the size of the tumor and degree of attachment to the carotid vessel. Shamblin classification (types 1-3) has helped guide resection: type 1 (relatively small, minimally attached), type 2 (larger, moderately attached), and type 3 (large with carotid incarceration). Type $3 \mathrm{CBTs}$ are difficult to resect and may require vascular sacrifice in order to obtain a gross-total resection. ${ }^{37}$

\section{Limitations}

This study is inherently limited due to publication and selection bias of any review of the literature. These studies may underreport complications and may not accurately represent surgical morbidity of pediatric paragangliomas. Lastly, the mean overall follow-up in our systematic review was 39.5 months; therefore, a true estimate of recurrence risk is difficult to predict.

\section{Conclusions}

CBTs in a pediatric population can cause significant morbidity and mortality if untreated, but the tumors usually have a good prognosis with surgical interventions. Most tumors present as asymptomatic palpable neck masses but can cause morbidity due to mass effect or secretion of catecholamines that cause increased blood pressure, palpations, and cardiac arrhythmias. This review shows that metastasis in this tumor type is rare and that surgical intervention has been successful as the primary treatment method. Our case series demonstrates that preoperative embolization is beneficial in the management of CBTs by reducing intraoperative bleeding, which may lead to better resection and fewer complications. Our treatment paradigm can be seen in Fig. 4.

\section{References}

1. Adams ML, Meyer ER, Sewing BN, Cicero TJ: Effects of nitric oxide-related agents on rat testicular function. J Pharmacol Exp Ther 269:230-237, 1994

2. Bakshi SS, Kumar TL: Carotid body tumor. J Pediatr Hematol Oncol 40:143-144, 2018

3. Bastounis E, Maltezos C, Pikoulis E, Leppäniemi AK, Klonaris C, Papalambros E: Surgical treatment of carotid body tumours. Eur J Surg 165:198-202, 1999

4. Bensaid B, Khalil J, Ould Salek E, El Khaloufi S, Elidrissi R, Lekehal B, et al: A rare case of a massive carotid body tumor in a 3-year-old infant: case presentation and a literature review. Ann Vasc Surg 29:1661.e9-1661.e15, 2015

5. Boscarino G, Parente E, Minelli F, Ferrante A, Snider F: An evaluation on management of carotid body tumour (CBT). A twelve years experience. G Chir 35:47-51, 2014

6. Chambers RG, Mahoney WD: Carotid body tumors. Am J Surg 116:554-558, 1968

7. Chen H, Sippel RS, O'Dorisio MS, Vinik AI, Lloyd RV, Pacak K: The North American Neuroendocrine Tumor Society consensus guideline for the diagnosis and management of neuroendocrine tumors: pheochromocytoma, paraganglioma, and medullary thyroid cancer. Pancreas 39:775-783, 2010

8. Dickinson PH, Griffin SM, Guy AJ, McNeill IF: Carotid body tumour: 30 years experience. Br J Surg 73:14-16, 1986

9. Dixon JL, Atkins MD, Bohannon WT, Buckley CJ, Lairmore TC: Surgical management of carotid body tumors: a 15 -year single institution experience employing an interdisciplinary approach. Proc Bayl Univ Med Cent 29:16-20, 2016

10. Fennessy BG, Kozakewich HP, Silvera M, Frerichs K, Lillhei $\mathrm{CW}$, Poe D, et al: The presentation and management of multiple paraganglioma in head and neck. Ir J Med Sci 180:757760,2011

11. Fishbein L, Orlowski R, Cohen D: Pheochromocytoma/ paraganglioma: review of perioperative management of blood pressure and update on genetic mutations associated with pheochromocytoma. J Clin Hypertens (Greenwich) 15:428-434, 2013

12. Garg MK, Kharb S, Brar KS, Gundgurthi A, Mittal R: Medical management of pheochromocytoma: Role of the endocrinologist. Indian J Endocrinol Metab 15 (Suppl 4):S329S336, 2011

13. Georgiadis GS, Lazarides MK, Tsalkidis A, Argyropoulou P, Giatromanolaki A: Carotid body tumor in a 13-year-old child: case report and review of the literature. J Vasc Surg 47:874-880, 2008

14. Gujrathi CS, Donald PJ: Current trends in the diagnosis and management of head and neck paragangliomas. Curr Opin Otolaryngol Head Neck Surg 13:339-342, 2005

15. Hajnzić TF, Kruslin B, Belicza M: Carotid body paraganglioma in a nine-year-old boy with extensive pulmonary metastases. Med Pediatr Oncol 32:399-400, 1999

16. Hallett JW Jr, Nora JD, Hollier LH, Cherry KJ Jr, Pairolero PC: Trends in neurovascular complications of surgical management for carotid body and cervical paragangliomas: a fifty-year experience with 153 tumors. J Vasc Surg 7:284291, 1988

17. Ifeoluwa A, Lázár I, Szövördi É, Karosi T: Management of carotid body tumor in pediatric patients: A case report and review of the literature. Int J Pediatr Otorhinolaryngol 93:47-52, 2017

18. Javid H, Dye WS, Hunter JA, Najafi H, Julian OC: Surgical management of carotid body tumor. Arch Surg 95:771-779, 1967

19. Karatas E, Sirikci A, Baglam T, Mumbuc S, Durucu C, Tutar E, et al: Synchronous bilateral carotid body tumor and vagal paraganglioma: a case report and review of literature. Auris Nasus Larynx 35:171-175, 2008

20. Knight TT Jr, Gonzalez JA, Rary JM, Rush DS: Current concepts for the surgical management of carotid body tumor. Am J Surg 191:104-110, 2006

21. Li J, Wang S, Zee C, Yang J, Chen W, Zhuang W, et al: Preoperative angiography and transarterial embolization in the management of carotid body tumor: a single-center, 10-year experience. Neurosurgery 67:941-948, 2010

22. Lustrin ES, Palestro C, Vaheesan K: Radiographic evaluation and assessment of paragangliomas. Otolaryngol Clin North Am 34:881-906, vi, 2001

23. Manjaly JG, Alexander VR, Pepper CM, Ifeacho SN, Hewitt RJ, Hartley BE: Primary cervical ganglioneuroblastoma. Int J Pediatr Otorhinolaryngol 79:1007-1012, 2015

24. Metheetrairut C, Chotikavanich C, Keskool P, Suphaphongs N: Carotid body tumor: a 25-year experience. Eur Arch Otorhinolaryngol 273:2171-2179, 2016

25. Monro RS: The natural history of carotid body tumours and their diagnosis and treatment; with a report of five cases. $\mathbf{B r}$ J Surg 37:445-453, 1950

26. Newland MC, Hurlbert BJ: Chemodectoma diagnosed by hypertension and tachycardia during anesthesia. Anesth Analg 59:388-390, 1980

27. Nora JD, Hallett JW Jr, O’Brien PC, Naessens JM, Cherry KJ Jr, Pairolero PC: Surgical resection of carotid body tumors: long-term survival, recurrence, and metastasis. Mayo Clin Proc 63:348-352, 1988

28. Offergeld C, Brase C, Yaremchuk S, Mader I, Rischke HC, Gläsker S, et al: Head and neck paragangliomas: clinical 
and molecular genetic classification. Clinics (São Paulo) 67 (Suppl 1):19-28, 2012

29. O'Neill S, O’Donnell M, Harkin D, Loughrey M, Lee B, Blair P: A 22-year Northern Irish experience of carotid body tumours. Ulster Med J 80:133-140, 2011

30. Ophir D: Familial multicentric paragangliomas in a child. J Laryngol Otol 105:376-380, 1991

31. Pellitteri PK, Rinaldo A, Myssiorek D, Jackson CG, Bradley PJ, Devaney KO, et al: Paragangliomas of the head and neck. Oral Oncol 40:563-575, 2004

32. Persky MS, Setton A, Niimi Y, Hartman J, Frank D, Berenstein A: Combined endovascular and surgical treatment of head and neck paragangliomas - a team approach. Head Neck 24:423-431, 2002

33. Plukker JT, Brongers EP, Vermey A, Krikke A, van den Dungen JJ: Outcome of surgical treatment for carotid body paraganglioma. Br J Surg 88:1382-1386, 2001

34. Power AH, Bower TC, Kasperbauer J, Link MJ, Oderich $\mathrm{G}$, Cloft H, et al: Impact of preoperative embolization on outcomes of carotid body tumor resections. J Vasc Surg 56:979-989, 2012

35. Robison JG, Shagets FW, Beckett WC Jr, Spies JB: A multidisciplinary approach to reducing morbidity and operative blood loss during resection of carotid body tumor. Surg Gynecol Obstet 168:166-170, 1989

36. Saldana MJ, Salem LE, Travezan R: High altitude hypoxia and chemodectomas. Hum Pathol 4:251-263, 1973

37. Shamblin WR, ReMine WH, Sheps SG, Harrison EG Jr: Carotid body tumor (chemodectoma). Clinicopathologic analysis of ninety cases. Am J Surg 122:732-739, 1971

38. Struffert T, Deuerling-Zheng Y, Engelhorn T, Kloska S, Gölitz P, Bozzato A, et al: Monitoring of balloon test occlusion of the internal carotid artery by parametric color coding and perfusion imaging within the angio suite: first results. Clin Neuroradiol 23:285-292, 2013

39. Tekautz TM, Pratt CB, Jenkins JJ, Spunt SL: Pediatric extraadrenal paraganglioma. J Pediatr Surg 38:1317-1321, 2003

40. Thompson JW, Cohen SR: Management of bilateral carotid body tumors and a glomus jugulare tumor in a child. Int $\mathbf{J}$ Pediatr Otorhinolaryngol 17:75-87, 1989
41. van der Mey AG, Frijns JH, Cornelisse CJ, Brons EN, van Dulken H, Terpstra HL, et al: Does intervention improve the natural course of glomus tumors? A series of 108 patients seen in a 32-year period. Ann Otol Rhinol Laryngol 101:635-642, 1992

42. Vogel TR, Mousa AY, Dombrovskiy VY, Haser PB, Graham AM: Carotid body tumor surgery: management and outcomes in the nation. Vasc Endovascular Surg 43:457-461, 2009

43. Williams MD, Phillips MJ, Nelson WR, Rainer WG: Carotid body tumor. Arch Surg 127:963-968, 1992

44. Zaupa P, Höllwarth ME: Carotid body paraganglioma: rare tumor in a 15-year-old adolescent boy. J Pediatr Surg 42:E13-E17, 2007

45. Zeitler DM, Glick J, Har-El G: Preoperative embolization in carotid body tumor surgery: is it required? Ann Otol Rhinol Laryngol 119:279-283, 2010

\section{Disclosures}

The authors report no conflict of interest concerning the materials or methods used in this study or the findings specified in this paper.

\section{Author Contributions}

Conception and design: Shah, Jernigan. Acquisition of data: Niazi. Drafting the article: Kuchakulla, Shah, Armstrong. Critically revising the article: Bhatia.

\section{Correspondence}

Toba N. Niazi: University of Miami, Miami, FL. toba.niazi@ mch.com. 